\title{
BMJ Open Reliability and validity of the Turkish version of the Individual-Level Abortion Stigma Scale: a methodological study
}

\author{
Aynur Cetinkaya, Dilek Özmen, Fatma Uyar, Ali Tayhan
}

To cite: Cetinkaya A, Özmen D, Uyar F, et al. Reliability and validity of the Turkish version of the Individual-Level Abortion Stigma Scale: a methodological study. BMJ Open 2019;9:e024686. doi:10.1136/ bmjopen-2018-024686

- Prepublication history for this paper is available online. To view these files, please visit the journal online (http://dx.doi. org/10.1136/bmjopen-2018024686).

Received 12 June 2018 Revised 19 December 2018 Accepted 18 February 2019
Check for updates

(C) Author(s) (or their employer(s)) 2019. Re-use permitted under CC BY-NC. No commercial re-use. See rights and permissions. Published by BMJ.

Faculty of Health Sciences, Manisa Celal Bayar University, Manisa, Turkey

Correspondence to Dr Aynur Cetinkaya; aynur.cetinkaya@cbu.edu.tr and Dr Dilek Özmen;

ozmendilek@yahoo.com

\section{ABSTRACT}

Objectives The aim of this study was to assess the reliability and validity of the Turkish version of the Individual-Level Abortion Stigma Scale.

Setting Three hospitals affiliated to Public Hospitals Union General Secretariat in Manisa, a city located in Western Turkey.

Design This was a methodological study.

Participants A total of 230 women aged $22-49$ years who previously underwent abortion and volunteered to participate in the study.

Primary and secondary outcome measures Data analysis was performed using the SPSS and LISREL software. The Content Validity Index was calculated based on the values obtained from expert opinions. In the reliability analysis, Cronbach's alpha values were calculated for the overall scale and its subscales. To test the stability of the scale over time, the scale was readministered to 30 women in the study 15 days later and the test-retest values (Pearson's correlation coefficients) were determined. In the validity analysis, the exploratory and confirmatory factor analyses were performed. In the exploratory factor analysis, the principal component analysis was performed using the varimax rotation and the factor loading of the scale was examined. Confirmatory factor analysis was performed to investigate the item-factor construct of the scale.

Results The Content Validity Index was calculated as 0.86 . The Cronbach's alpha values ranged between 0.83 and 0.94 . The item-total correlation coefficients ranged between 0.36 and 0.72 , and the test-retest reliability was 0.96 for the overall scale and its subscales $(p<0.05)$. The total variance revealed by five factors was $75 \%$. Confirmatory factor analysis of the scale revealed an acceptable compliance level (root mean square error of approximation $=0.092, \chi^{2} / \mathrm{df}=2.91$, Goodness of Fit Index=0.831, Comparative Fit Index=0.928, $p<0.001$ ). Conclusions The results suggest that this scale has the potential for use in research and clinical settings to measure abortion stigma among women.

\section{INTRODUCTION}

Abortion is a component of women's health. However, unsafe abortion continues to be an important reproductive health problem and a cause of mortality and morbidity in the world, particularly in low/middle-income countries. Despite simple, safe and effective interventions, 21.6million unsafe abortions take place each year in the world. ${ }^{1}$ According to Turkey

\section{Strengths and limitations of this study}

In Turkey, there is no Turkish tool to measure whether women experience abortion stigma, and this is the first study regarding the subject.

- The Individual-Level Abortion Stigma Scale consists of short and understandable statements. Thanks to this aspect of the scale, it can provide great convenience for researchers.

- The Individual-Level Abortion Stigma Scale is a reliable and valid questionnaire to assess stigmatisation of abortion in women.

- The limitation of this study is that the parallel form reliability analysis was not performed because there is no other tool used to measure stigma regarding abortion.

Demographic and Health Survey (TDHS) 2013 results, $14 \%$ of married women in Turkey had induced abortion during the fertility period, and $2 \%$ of these abortions occurred in unsafe conditions and caused the death of the mothers. ${ }^{2}$

One of the key issues discussed in multisided debates on abortion in the world is the stigmatisation of women who have an abortion. Stigma is a mark of disgrace, humiliation or disparagement setting a person apart from others. ${ }^{3}$ Internalisation of stigma into the society leads individuals towards severe trauma. ${ }^{4}$ What lies behind stigma are negative beliefs and the prejudices resulting from these negative beliefs. ${ }^{5}$ What is emphasised by stigma is that the person or the group stigmatised is different from others in the society. Moreover, several negative features are attributed to those stigmatised..$^{6-12}$ Abortion stigma is a global phenomenon, which is discrediting of individuals. ${ }^{13}$ The literature reports that women are generally fearful of judgement from others for having an abortion $^{14}$ and feel a high level $(43 \%, 66 \%)$ of internal abortion stigma. ${ }^{13} 15$

As in all health cases, the first step in the prevention of stigma will be raising awareness. ${ }^{16}$ Therefore, considering the idea that measuring the tendency of stigmatisation is 
the first step in raising social awareness, we planned to evaluate the reliability and validity of the Turkish version of the Individual-Level Abortion Stigma Scale (ILASS) to assess the individualised internalised perception of abortion stigma in women who have undergone abortion. This scale is a theory-based, multidimensional and valid measurement tool to measure stigma in women who have undergone abortion. ${ }^{17}$ In the literature, there is limited understanding about how health-related stigma has developed in a very wide sociocultural context, in particular, how abortion stigma has rooted in several societies and how abortion stigma has affected and will affect these societies. ${ }^{18}$ In Turkey, there is no Turkish tool to measure whether women experience abortion stigma. In this study, we aimed to adapt the ILASS developed by Cockrill $e t \mathrm{al}^{17}$ into Turkish and to test the validity and reliability of the Turkish version of the scale.

\section{METHODS}

\section{Design and survey population}

This methodological study was carried out between June 2014 and November 2014 in three hospitals affiliated to Public Hospitals Union General Secretariat in Manisa and included women aged 22-49 years who have previously undergone abortion. Manisa is a city located in western Turkey. The inclusion criteria for the study were as follows: having undergone an abortion; being in the fertility age; presenting to a hospital for any reason other than pregnancy, childbirth or abortion; and volunteering to participate in the study. The study sample included 230 women selected by the self-selection sampling method. Women applied to the hospitals during the data collection periods $(n=230)$. To determine the optimal sample size of this study, we referred to the frequently promoted n:t rule of thumb concerning the minimum recommended ratio of sample size (n) to the number of parameters ( $t$ ) to be estimated in structural equation modelling (SEM). Various n:t ratios have been proposed in the SEM literature; for instance, in the review of Bagozzi and $\mathrm{Yi}_{1}{ }^{19}$ the typical 10:1 ratio was suggested, whereas the ratios 3:1, 5:1 and 2:1 have also been suggested. Our conceptual SEM has 16 parameters for the measurement model of the latent variables and 16 parameters for the path analysis model of the latent variable links. Thus, with $t=32$, we estimated a minimal sample size of $32 \times 10$, or $n=320$ for a 10:1 ratio. Our sample size was higher than this minimum sample size.

\section{Data collection tools}

\section{Personal information form}

The sociodemographic characteristics of the participants such as age, education level and the number of abortions and their husbands' sociodemographic characteristics were assessed using 14 questions.

\section{Individual-Level Abortion Stigma Scale}

The Likert-type scale consists of 4 subscales and 20 items. Items 8-10 in the isolation subscale are rated on a 4-point
Likert scale, ranging from 0 to 3 , while all the other items are rated on a 5-point Likert scale, ranging from 0 to 4 . The scoring of the scale varies from one subscale to another. The subscales were as follows: 'worries about judgement', 'isolation', 'self-judgement' and 'community condemnation'. The higher the score obtained from the scale is, the more the woman feels she is stigmatised. The items $8-13$ and 15 of the ILASS are reverse scored. High scores obtained from the overall scale and from the subscales indicate that the woman considers herself as highly stigmatised. ${ }^{17}$

During the data collection process, the participants were informed about who the researchers were and the purpose of the study, and then their written informed consent was obtained. Data collection was performed in the outpatient rooms. The data were collected by the paper-and-pencil method from the patients who were able to write. It took approximately $20 \mathrm{~min}$ to interview each woman.

\section{Language and content validity}

In the linguistic adaptation of the scale, the standard methods were performed step by step. In the first step, the scale was translated from English, the language of the original scale, to Turkish by five native speakers of Turkish. Then, two faculty members evaluated the translations for each item to determine which one was the most appropriate Turkish translation, and then the Turkish version of the scale was created. This scale was then translated back to English by an expert whose native language was English. This back-translated version was compared with the original version of the scale by two lecturers with a good command of English and Turkish. Subsequently, the items of the scale were discussed, and after reaching a consensus, the Turkish version of the scale was reviewed for the last time and the final form of the scale was produced. After the language adaptation of the scale, expert opinions for the final version of the scale were obtained from 10 faculty members. The experts were asked to rate the scale between 1 and 4 in terms of language/expression appropriateness and content appropriateness. The Content Validity Index (CVI) was calculated based on the obtained values and found to be 0.86 . Consistent with the opinions of the experts, two items were revised and the necessary changes were made. No items were removed from the scale.

After the final form was pilot tested with 15 women who had undergone abortion, the final step of the language adaptation was achieved. After the preliminary application of the scale, no negative feedback was received from the pilot-tested women regarding the clarity of the items. As the items were understandable, we did not perform cognitive interviews with the pilot-tested sample. Data obtained from the women who were pilot tested were not included in the analysis. 


\section{Statistical analysis}

After administering the ILASS to the target group, the statistical package programs (LISREL V.8.54, SPSS V.20.0) were used for data analysis. To achieve the score distribution of the scale, the mean scores and SD for the overall scale and its subscales were calculated. In the reliability analysis, Cronbach's alpha values were calculated for the overall scale and its subscales. Cronbach's alpha values $>0.70$ were considered to be sufficient. ${ }^{20}$ To test the stability of the scale over time, the scale was readministered to 30 women in the study 15 days later, and the testretest values (Pearson's correlation coefficients) were determined. It has been recommended that stability must be assessed over a period of 2-6 weeks administration of the scale. ${ }^{21}$

In the validity analysis, the exploratory and confirmatory factor analyses were performed. Cross-cultural scale adaptation studies have recommended that confirmatory factor analysis must be performed; however, if the model for the original scale-size structure is not verified or if it does not yield high fit indices in the confirmatory factor analysis, then it is recommended to perform the exploratory factor analysis. ${ }^{22}$ Consistent with the aim of this study, before performing the exploratory factor analysis, the four-subscale model in the original scale was evaluated by the confirmatory factor analysis. However, because of the poor fit indices of the four-subscale model (root mean square error of approximation [RMSEA] $=0.141$, $\chi^{2} / \mathrm{df}=5.52 \quad\left(\chi^{2}=905.96, \mathrm{df}=164\right)$, Comparative Fit Index $[\mathrm{CFI}]=0.826)$, the confirmatory factor analysis was performed for the five-factor structure obtained after the exploratory factor analysis.

In the exploratory factor analysis, the principal component analysis was performed using the varimax rotation and the factor loading of the scale was examined. After the calculation, the Kaiser-Meyer-Olkin (KMO) value was calculated to assess the adequacy of the sample size. In addition, the Bartlett's test of sphericity was used to determine the analytical appropriateness of the scale items (fitness of the correlation matrix of the variables to the unit matrix). The KMO value is supposed to be $p>0.05$, and the result of the Bartlett's sphericity test is supposed to be $\mathrm{p}<0.05 .^{23}$ The confirmatory factor analysis was performed to investigate the item-factor construct of the scale. First, the exploratory factor analysis was performed, in which after evaluating all the scale items, five factors with an eigenvalue $>1$ were obtained. After the exploratory factor analysis, the confirmatory factor analysis was performed to evaluate whether the five-factor construct fitted the original scale without disrupting the original item-factor structure (with only two components produced in one subscale). Of the fit indices, the $\mathrm{X}^{2} / \mathrm{df}$, RMSEA, CFI and the standardised root mean residual (SRMR) values were given. For these values, several fit and cut-off points have been indicated in the literature. In general, values $<3$ for $\chi^{2} / \mathrm{df}$ values $<0.08$ for RMSEA, values $<0.10$ for SRMR and values $>0.90$ for CFI indicate good fit. ${ }^{24}$ In addition, known groups' validity was computed for ILASS. This is a typical method to support construct validity. The known groups' method was evaluated by performing an independent t-test and one-way analysis of variance and post hoc Tukey's Honestly significant difference (HSD) test to examine the difference in the mean ILASS scores between women. A $p<0.05$ was set for analysing significant differences.

\section{Patient and public involvement}

Patients were not involved in the design of this study. Public health authorities in Manisa (Public Hospitals Union General Secretariat) were involved in the conduct of the study.

The validity and reliability of the Turkish version of the scale were evaluated after obtaining permission from Cockrill via email.

\section{RESULTS}

\section{Sociodemographic findings}

The mean age of the women participants was $39.4 \pm 7.4$ years (range: $22-49$ years). There were $51.3 \%$ of women in the $41-49$ years age group, $33.9 \%$ in the $31-40$ years age group and $14.8 \%$ in the $22-30$ years age group. Among the participating women, the majority $(91.3 \%)$ were married, $59.6 \%$ were primary school graduates, $16.1 \%$ were high school graduates, $24.3 \%$ were university graduates, $56.5 \%$ were housewives (not employed), $83.9 \%$ had a nuclear family and $64.3 \%$ had an income equal to their expenses. The mean number of births they had was $2.5 \pm 1.5$ (range: $0-12$ ). The women stated that they underwent an abortion in a health institution. Among the spouses of the women, $40.4 \%$ were primary school graduates, $36.6 \%$ were high school graduates, $23 \%$ were university graduates and $13.9 \%$ were currently unemployed.

\section{Score distributions and reliability analysis of the scale}

The mean subscale scores and the SD of the ILASS are shown in table 1, and the mean score for the overall scale was $1.46 \pm 0.56$. The Cronbach's alpha values of the fivefactor scale were 0.88 for the 'isolation' subscale, 0.89 for the 'worries about judgement' subscale, 0.83 for the 'self-judgement' subscale, 0.91 for the 'community

Table 1 Descriptive analysis of the ILASS and its subscales and Cronbach's values $(n=230)$

\begin{tabular}{llll}
\hline The subscales and overall scale & $\begin{array}{l}\text { Item } \\
\text { numbers }\end{array}$ & $\begin{array}{l}\text { Item } \\
\text { mean } \pm \text { SD }\end{array}$ & $\begin{array}{l}\text { Cronbach's } \\
\text { alpha }\end{array}$ \\
\hline Isolation & 6 items & $1.23 \pm 0.83$ & 0.88 \\
\hline Worries about judgement & 7 items & $0.82 \pm 0.63$ & 0.89 \\
\hline ...by close relatives/loved ones & 4 items & $1.07 \pm 0.94$ & 0.94 \\
\hline ...by distant relatives/people & 3 items & $0.49 \pm 0.36$ & 0.91 \\
\hline Self-judgement & 5 items & $2.16 \pm 1.03$ & 0.83 \\
\hline Community condemnation & 2 items & $2.59 \pm 1.19$ & 0.84 \\
\hline Overall scale & 20 items & $1.46 \pm 0.56$ & 0.85 \\
\hline
\end{tabular}

ILASS, Individual-Level Abortion Stigma Scale. 
Table 2 Correlation between the first and second administrations of the Individual-Level Abortion Stigma Scale (ILASS) $(n=30)$

\begin{tabular}{|c|c|c|}
\hline $\begin{array}{l}\text { The subscales and the overall scale at the } \\
\text { first and second administrations of the ILASS }\end{array}$ & $\mathbf{r}$ & $P$ value \\
\hline Isolation & 0.76 & 0.000 \\
\hline \multicolumn{3}{|l|}{ Worries about judgement } \\
\hline ...by close relatives/loved ones & 0.80 & 0.000 \\
\hline ...by distant relatives/people & 0.54 & 0.002 \\
\hline Self-judgement & 0.94 & 0.000 \\
\hline Community condemnation & 0.63 & 0.000 \\
\hline Overall scale & 0.96 & 0.000 \\
\hline
\end{tabular}

condemnation' subscale and 0.85 for the overall scale (table 1). The item-total correlation coefficients of the scale ranged between 0.36 and $0.72(p<0.001)$. As the item-total correlation coefficient was not $<0.30$ for any of the items, no item was removed from the scale.

To test the stability of the scale over time, the scale was readministered to 30 women in the study 15 days later.
The test-retest correlation coefficient was 0.96, and the test-retest correlation coefficients for the subscales of the scale were calculated to range between 0.54 and 0.94 $(\mathrm{p}<0.005$, table 2$)$.

Validity analysis: exploratory and confirmatory factor analysis In the exploratory factor analysis, five factors with an eigenvalue $>1$ were obtained. The $\mathrm{KMO}$ value $(0.814)$ and the Bartlett's sphericity test were found to be satisfactory and compatible at $\mathrm{p}<0.001$ for the factor analysis. The items forming the five-factor structure produced by the exploratory factor analysis accounted for $75 \%$ of the variance. Because the factor loads were between 0.35 and 0.91 , in other words, they were above 0.30 , no item was removed from the scale. ${ }^{25}$ When the distribution of these five factors was compared with that of the original scale, it was observed that two factors were included in the 'worries about judgement' subscale and that the structures of the other factors were similar to those of the original scale. In other words, the distribution of the factors produced by the exploratory factor analysis was consistent with the factor structure of the original scale (table 3 ). The factors were termed according

Table 3 Exploratory factor analysis results of the ILASS

\begin{tabular}{|c|c|c|c|c|c|}
\hline \multirow{2}{*}{$\begin{array}{l}\text { Original subscales } \rightarrow \\
\text { Produced factors } \rightarrow\end{array}$} & \multirow{2}{*}{$\frac{\text { Isolation }}{\text { F1 }}$} & \multicolumn{2}{|c|}{$\begin{array}{l}\text { Worries about } \\
\text { judgement }\end{array}$} & \multirow{2}{*}{$\begin{array}{l}\begin{array}{l}\text { Self- } \\
\text { judgement }\end{array} \\
\text { F4 }\end{array}$} & \multirow{2}{*}{$\begin{array}{l}\begin{array}{l}\text { Community } \\
\text { condemnation }\end{array} \\
\text { F5 }\end{array}$} \\
\hline & & F2 & F3 & & \\
\hline \multicolumn{6}{|l|}{ Items } \\
\hline $9^{*}$ I told someone I was close (close others) how I felt about my abortion & 0.864 & 0.071 & 0.096 & -0.004 & -0.106 \\
\hline $8^{\star}$ I talked with someone I was close (close others) about my abortion & 0.842 & 0.052 & 0.106 & 0.046 & -0.097 \\
\hline $12^{*}$ I trust my relatives (significant others) who knew I underwent abortion & 0.814 & 0.132 & -0.056 & 0.068 & -0.037 \\
\hline $13^{*}$ I felt the support of my relatives (significant others) when I had my abortion & 0.756 & 0.076 & -0.103 & 0.048 & 0.006 \\
\hline $\begin{array}{l}10^{*} \text { I felt the support of someone I was close (close others) with at the time of } \\
\text { my abortion }\end{array}$ & 0.728 & -0.004 & -0.023 & 0.011 & 0.054 \\
\hline 5 Other people might gossip about me & 0.153 & 0.873 & 0.221 & 0.190 & 0.011 \\
\hline 7 Other people might judge me negatively & 0.087 & 0.872 & 0.187 & 0.208 & 0.074 \\
\hline 6 I might be rejected by the person I love & 0.086 & 0.210 & 0.893 & -0.009 & 0.043 \\
\hline 2 My abortion might adversely affect my relationship with someone I love & 0.041 & 0.201 & 0.880 & -0.012 & -0.001 \\
\hline 18 I felt guilty & -0.026 & 0.168 & -0.002 & 0.869 & 0.142 \\
\hline 17 I felt selfish & -0.041 & 0.238 & 0.075 & 0.850 & 0.119 \\
\hline 16 I felt ashamed because of my abortion & -0.001 & 0.230 & -0.019 & 0.839 & 0.150 \\
\hline 14 I felt like a bad person & -0.028 & 0.075 & -0.016 & 0.764 & 0.169 \\
\hline $15^{\star}$ I was sure I had made the right decision & 0.232 & 0.247 & -0.166 & 0.355 & -0.229 \\
\hline 19 Abortion is always wrong & -0.063 & 0.090 & 0.227 & -0.012 & 0.886 \\
\hline 20 Abortion is equivalent to murder & -0.052 & 0.145 & 0.251 & 0.041 & 0.866 \\
\hline
\end{tabular}

$\mathrm{KMO}=0.814$; Bartlett's test of sphericity: $\mathrm{p}<0.001$. The bold values indicate the highest factor load.

${ }^{\star}$ Reverse coded items.

†Percentage of cumulative variance for five factors $=75 \%$.

ILASS, Individual-Level Abortion Stigma Scale; KMO, Kaiser-Meyer-Olkin. 
Table 4 Confirmatory factor analysis model summary index scores of the Individual-Level Abortion Stigma Scale (ILASS)

\begin{tabular}{lc}
\hline Criteria & ILASS \\
\hline$\chi^{2}(p)$ & 467.05 \\
df & 160 \\
$\chi^{2} / d f$ & 2.91 \\
$\begin{array}{l}\text { Root mean square error of } \\
\text { approximation }\end{array}$ & 0.092 \\
Comparative Fit Index & 0.928 \\
Goodness of Fit Index & 0.831 \\
Standardised root mean residual & 0.065 \\
\hline
\end{tabular}

to the subscales of the original scale. The items included in the 'worries about judgement' subscale of the original scale were loaded onto two factors in this study. Therefore, this subscale in the Turkish version had the following two components: 'worries about judgement by close relatives/ loved ones' and 'worries about judgement by distant relatives/people.'

After the confirmatory factor analysis, the following values were determined for the overall model: RMSEA $=0.092, \quad \chi^{2} / \mathrm{df}=2.91 \quad\left(\chi^{2}=467.05, \quad \mathrm{df}=160\right)$, CFI $=0.928$ and SRMR $=0.065$ (table 4 ). Since the error variance of item 15 was 0.93 in the confirmatory factor analysis, the confirmatory factor analysis was performed again after removing this item from the analysis; however, as there was no change in the compliance index, it was decided to retain it as in the original scale.

The known groups' method was evaluated by univariate analysis. At the individual level, the ILASS varied significantly with the women's age, education level, working status and time since abortion $(\mathrm{p}<0.05$, table 5$)$.

\section{DISCUSSION}

The sociodemographic characteristics of the women in the sample group of the present study were found to

Table 5 Analysis assessing the differences in mean scores on the ILASS, according to selected participant characteristics $(\mathrm{n}=230)$

\section{Full Scale Scores}

\section{Characteristics}

n Mean \pm SD

Statistical test ${ }^{*}$ and

Age (years) $\dagger$

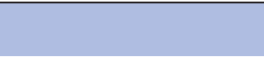

$\begin{array}{lrlr}22-30(a) & 34 & 33.08 \pm 10.89 & F=4.040 \\ 31-40 \text { (b) } & 78 & 33.74 \pm 10.49 & P=0.019 \\ 41-49 \text { (c) } & 118 & 37.16 \pm 8.81 & a=b>c \neq\end{array}$

Education level

Primary school graduate (a)

High school graduate (b) $\quad 37$

University graduate (c) 56

Working status

$\begin{array}{lccc}\text { Employed } & 100 & 33.88 \pm 9.52 & \mathrm{t}=2.071 \\ \text { Not employed } & 130 & 36.57 \pm 9.99 & \mathrm{P}=0.039\end{array}$

Income statement

\begin{tabular}{|c|c|c|c|}
\hline 'An income low to expenses' (a) & 52 & $38.67 \pm 9.60$ & $F=5.249$ \\
\hline 'An income equal to expenses' (b) & 148 & $35.00 \pm 9.17$ & $P=0.006$ \\
\hline 'An income high to expenses' (c) & 30 & $31.73 \pm 12.02$ & $a>b=c \ddagger$ \\
\hline 1 & 169 & $35.81 \pm 9.74$ & $t=1.040$ \\
\hline$\geq 2$ & 61 & $34.27 \pm 10.16$ & $P=0.299$ \\
\hline$<4$ years & 53 & $32.18 \pm 10.88$ & $F=4.681$ \\
\hline 4-9years & 60 & $35.00 \pm 10.59$ & $P=0.010$ \\
\hline$>9$ years & 117 & $37.06 \pm 8.60$ & $a<b=c \ddagger$ \\
\hline
\end{tabular}

*Statistical test F: one-way ANOVA test, t: independent t-test.

†Pearson's correlation coefficient was used to investigate the correlation between the women's ILASS scores and age; $r=0.201, p=0.002$.

‡Post hoc test (Tukey's HSD).

ANOVA, analysis of variance; ILASS, Individual-Level Abortion Stigma Scale. 
be similar to those of the women according to the data in TDHS, 2013 (68\% were married, 35\% were primary school graduates, $31 \%$ were high school graduates, $31.1 \%$ were employed and $2.2 \%$ had children). ${ }^{2}$

Methodological studies recommend that the sample size should be a minimum of 5 or 10 -fold the number of items in the scale and not $<200 .{ }^{20}{ }^{26}$ In the present study, the sample size was 10-fold the number of parameters calculated for the confirmatory factor analysis. Language adaptation and content validity studies of the scale were conducted. The fact that the CVI of the scale in the present study (0.86) was above the value recommended in the literature (0.80) suggests that there was a consensus among the experts and that the items of the scale were appropriate for the purpose of measuring the tool. ${ }^{27}$ After the pilot testing, the mean scores of the women participating in the study obtained from the ILASS and its subscales and the SD were evaluated. The mean score for the overall scale in the present study $(1.46 \pm 0.56)$ was consistent with that of the original scale $(1.4 \pm 0.63)$.

The results related to the reliability of the scale revealed that the Cronbach's alpha values of the five-factor scale ranged between 0.83 and 0.94 . The alpha value for the overall scale was 0.85 (above the recommended 0.70 cut-off point). In the study of Cockrill $e t a l,{ }^{17}$ the alpha values ranged between 0.80 and 0.90 for the subscales and 0.88 for the overall scale. The item-total correlation coefficients of the scale were between 0.36 and 0.72 . These results were found to be consistent with those reported by Cockrill $e t a l^{17}$ According to the test-retest results, there were strong or moderate correlations ( $\mathrm{r}$ values between 0.54 and 0.96 ) between the first and second values determined for all the factors of the scale. This result indicated that the Turkish version of the ILASS yielded similar values in repetitive measurements and was consistent.

The validity of the scale was evaluated using the exploratory and confirmatory factor analyses. The results of the exploratory factor analysis demonstrated that one dimension of the original scale was formed from two subfactors and the others remained the same. The "worries about judgement' subscale in the Turkish version has two components, 'by close relatives/loved ones' and 'by distant relatives/people'. In other words, three subscales in the Turkish version had the same structure as in the original scale, whereas one subscale included two subcomponents. However, the scale, as a whole, formed a structure consistent with the original scale. These results, which account for three-fourths $(75 \%)$ the total variance, were similar to those obtained from the original scale (the original scale accounts for $66 \%$ of the total variance and the factor loads range between 0.42 and 0.91$).{ }^{17}$ As in the original scale study, the scale in the present study can be said to consist of four primary factors.

The fact that one of the subscales in the original tool has two components in the Turkish version suggests that women in the Turkish society perceive worries about judgement by close relatives or loved ones differently from worries about judgement by distant relatives or people.
It also suggests that social pressure has features different from the pressure from the family. Another feature that distinguishes Turkish society from Western societies is the value given to the family and the family-related concepts (family council, neighbourhood pressure, etc). The literature states that the most important source of perception of stigma for a person is the person himself/herself, and another determinant factor of this perception is the immediate environment of the person. ${ }^{28}$ In conclusion, the exploratory factor analysis in this study demonstrated that the Turkish version of the scale had constructs similar to those of the original version and that one of the subscales of the original scale had two subcomponents in the Turkish version.

Confirmatory factor analysis was performed to test the fit of the scale's conceptual structure with the measurement model. The $\chi^{2} / \mathrm{df}$ value indicating the fit of the scale was 2.91, and it was considered to be in an acceptable range of fit. The comparative Goodness of Fit Index (CFI $=0.928$ ) was above the recommended value of 0.90 . On the other hand, although the RMSEA value (0.092) was at the borderline, it was still between 0.05 and $0.1 .^{24}$ Although several items with high autocorrelation were believed to have a negative effect on the results of the confirmatory factor analysis, the results obtained in this study showed that the model had an acceptable fit, which was also confirmed by the five subfactor structure.

At the individual level, the ILASS varied significantly with some of the women's characteristics (age, education level, etc). There are similarities ${ }^{17}$ and differences ${ }^{13} 17$ when compared with studies in the literature. The findings reflect the cultural differences compared with other studies. The ILASS can distinguish stigma scores according to certain characteristics of the women, such as age, education level and working status.

\section{Limitations}

Several limitations exist in the present study pertaining to the search strategy. A gold standard for abortion stigma is not available. The parallel form reliability analysis was not performed because of the lack of a tool to measure stigma about abortion.

\section{Conclusion}

This study was conducted to adapt the ILASS into Turkish and showed that the scale had adequate psychometric properties, it is a valid and reliable measurement tool, and it can be used in studies in this area in Turkey. It is recommended that researchers who intend to investigate the individualised internalised perception of abortion stigma in Turkish women should use the ILASS.

Contributors AÇ conceived and designed the study, contributed to acquisition of data, conducted the statistical analysis and interpretation of data, and drafted the manuscript. DÖ, FU and AT managed data collection and contributed to translations of the measure. AÇ and DÖ contributed to study design, acquisition of data and critically revised the manuscript for important intellectual content. All authors read and approved the final manuscript.

Funding The authors have not declared a specific grant for this research from any funding agency in the public, commercial or not-for-profit sectors. 
Competing interests None declared.

Patient consent for publication Obtained.

Ethics approval Before beginning the data collection process, approval from the Ethics Committee of Celal Bayar University School of Medicine and written permission from the Public Hospitals Union General Secretariat were obtained.

Provenance and peer review Not commissioned; externally peer reviewed.

Data sharing statement Data set for this study available on request from the corresponding author.

Open access This is an open access article distributed in accordance with the Creative Commons Attribution Non Commercial (CC BY-NC 4.0) license, which permits others to distribute, remix, adapt, build upon this work non-commercially, and license their derivative works on different terms, provided the original work is properly cited, appropriate credit is given, any changes made indicated, and the use is non-commercial. See: http://creativecommons.org/licenses/by-nc/4.0/.

\section{REFERENCES}

1. World Health Organization. Unsafe Abortion: Global and Regional Estimates of the Incidence of Unsafe Abortion and Associated Mortality in 2008. 6th edn. Geneva, 2011:1-2.

2. Hacettepe University Institute of Population Studies, 2013 Turkey Demographic and Health Survey. Hacettepe University Institute of Population Studies. Ankara, Turkey: T.R. Ministry of Development and TÜBITAK, 2014:90-8.

3. Corrigan PW, Edwards AB, Green A, et al. Prejudice, social distance, and familiarity with mental illness: Schizophr Bull, 2001:219-25.

4. Link BG, Phelan JC. Conceptualizing stigma. Annu Rev Sociol 2001;27:363-85.

5. Cam O, Bilge A. Beliefs and attitudes towards mental illness. Am J Psychiatry 2007;8:215-23.

6. Mak WW, Cheung RY, Law RW, et al. Examining attribution model of self-stigma on social support and psychological well-being among people with HIV+/AIDS. Soc Sci Med 2007;64:1549-59.

7. Larson JE, Corrigan PW. Psychotherapy for self-stigma among rural clients. J Clin Psychol 2010;66:524-36.

8. Markowitz FE. The effects of stigma on the psychological well-being and life satisfaction of persons with mental illness. $J$ Health Soc Behav 1998;39:335-47.

9. Vauth R, Kleim B, Wirtz M, et al. Self-efficacy and empowerment as outcomes of self-stigmatizing and coping in schizophrenia. Psychiatry Res 2007;150:71-80.

10. Rosenfield S. Labeling mental illness: the effect of received services and perceived stigma on life satisfaction. Am Sociol Rev 1997;62:660-72.
11. Greeff M, Uys LR, Wantland D, et al. Perceived HIV stigma and life satisfaction among persons living with HIV infection in five African countries: a longitudinal study. Int J Nurs Stud 2010;47:475-86.

12. Major B, O'Brien LT. The social psychology of stigma. Annu Rev Psychol 2005;56:393-421.

13. Oginni A, Ahmadu SK, Okwesa N, et al. Correlates of individual-level abortion stigma among women seeking elective abortion in Nigeria. Int J Womens Health 2018;10:361-6.

14. Altshuler AL, Ojanen-Goldsmith A, Blumenthal PD, et al. A good abortion experience: a qualitative exploration of women's needs and preferences in clinical care. Soc Sci Med 2017;191:109-16.

15. Shellenberg KM, Tsui AO. Correlates of perceived and internalized stigma among abortion patients in the USA: an exploration by race and Hispanic ethnicity. Int J Gynaecol Obstet 2012;118(Suppl 2)S152-S159.

16. Yaman E, Gungor H. Stigma Scale validity and reliability study. Journal of Values Education 2013;11:251-70.

17. Cockrill K, Upadhyay UD, Turan J, et al. The stigma of having an abortion: development of a scale and characteristics of women experiencing abortion stigma. Perspect Sex Reprod Health 2013;45:79-88.

18. Kumar A, Hessini L, Mitchell EM. Conceptualising abortion stigma. Cult Health Sex 2009;11:625-39.

19. Bagozzi RP, Yi Y. Specification, evaluation, and interpretation of structural equation models. J Acad Mark Sci 2012;40:8-34.

20. Tavșancll E. Attitude Measurement and Data Analysis with SPSS. 3rd edn. Ankara, Turkey, 2006:16-61.

21. Tabachnick BG, Fidell LS. Using Multivariate Statistics. 3rd edn. New York: Harper Collins College Publishers, 1996.

22. Cokluk Ö, Sekercioğlu G, Büyüköztürk S. Multivariate Statistics for Social Sciences: SPSS and LISREL Applications. 1st edn. Ankara, Turkey: Pegem Akademi Publishing, 2010:251-400.

23. Yong AG, Pearce S. A beginner's guide to factor analysis: focusing on exploratory factor analysis. Tutor Quant Methods Psychol 2013;9:79-94.

24. Dursun Y, Kocagöz E. Structural equation modeling and regression: a comparative analysis. Erciyes University Journal of Economics and Administrative Sciences 2010;35:1-17.

25. Dixon JK. Statistical methods for health care research. In: Munro BH ed. Exploratory Factor Analysis. Philadelphia: Lippincott Williams \& Wilkins, 2005:321-50.

26. Akgül A. Statistical analysis techniques in medical research SPSS applications. 3rd edn. Ankara, 2005:384.

27. Polit DF, Beck CT. The content validity index: Are you sure you know what's being reported? critique and recommendations. Res Nurs Health 2006;29:489-97.

28. Tașkın EO. Stigmatization and discrimination in mental illnesses. Taskın EO, ed. Stigma, Attitudes Toward Mental IIIness and Stigmatization. 1st edn. Turkey: Meta Printing İzmir, 2007:17-23. 